ARTÍCULOS / ARTICLES

RLA. Revista de Lingüística Teórica y Aplicada

Concepción (Chile), 52 (2), II Sem. 2014, pp. 13-40.

CL ISSN $0033-698 \mathrm{X}$

\title{
ESTADO DEL MAPUDUNGUN EN \\ COMUNIDADES PEWENCHES Y \\ LAFKENCHES DE LA REGIÓN DEL BÍO-BÍO: EL CASO DE LOS ESCOLARES
}

\author{
MAPUDUNGUN STATUS IN PEWENCHE AND \\ LAFKENCHE COMMUNITIES OF THE BÍO-BÍO REGION: \\ SCHOOL STUDENTS SITUATION
}

\author{
MARISOL HENRÍQUEZ BARAHONA \\ Universidad Católica de la Santísima Concepción. Concepción. Chile \\ mhenriquez@ucsc.cl
}

\section{RESUMEN}

El presente artículo tiene como propósito examinar la situación del mapudungun en comunidades mapuches de la Región del Bío-Bío, a través de la descripción y análisis de algunas dimensiones sociolingüísticas tales como: los hablantes de mapudungun en la comunidad, los niveles de competencia y el estado de la transmisión de la lengua al interior de la familia. La muestra está conformada por un grupo de 40 escolares mapuches de entre 12 y 15 años de edad, que se encuentran cursando $7^{\circ}$ y $8^{\circ}$ año básico en escuelas rurales adscritas al Programa de Educación Intercultural Bilingüe (PEIB). Esta muestra fue complementada con la participación de 4 educadores tradicionales de mapudungun que trabajan en las escuelas seleccionadas. Para la recolección del material se utilizó un cuestionario sociolingüístico y una entrevista focalizada, los cuales tuvieron como propósito recoger la mayor cantidad de información sociolingüística del hablante, su familia y la comunidad. El primero de ellos se aplicó a los escolares, mientras que la entrevista se realizó a los educadores tradicionales. En las comunidades de Alto Bío-Bío hemos observado que un gran número de pewenches aún conservan su lengua, aunque se advierten algunas diferencias en la mantención de ésta en las dos comunidades estudiadas (Butalelbun y Cauñicu). En Tirúa, en cambio, el contacto de lenguas ha dejado huellas en los procesos de mantención y elección lingüística, puesto que la mayoría de las familias transmite a sus hijos sólo la lengua oficial.

Palabras clave: Lenguas en contacto, mapudungun, transmisión intergeneracional, estado de la lengua. 


\begin{abstract}
This paper aims to examine the status of the Mapudungun language in mapuche communities of the Bío-Bío Region, through the description and analysis of some sociolinguistic dimensions such as: Mapudungun speakers in the community, level of proficiency and the state of the Mapudungun transmission of the language within the family. The sample is made up of 40 mapuche schoolchildren from 12 to 15 years old, in $7^{\text {th }}$ and $8^{\text {th }}$ grade at rural primary schools that are part of the Programa de Educación Intercultural Bilingüe (PEIB). This sample was complemented with the participation of 4 traditional Mapudungun teachers working in the participant schools. To collect the material, a sociolinguistic questionnaire and a focused interview were used, which intended to collect as much sociolinguistic information as possible, from the speakers, their families and the communities. The first instrument was applied to the school students, while the second instrument was applied to the traditional teachers. In the communities of Alto Bío-Bío, we have observed that a large number of Pewenches still maintain their language, although it should be noted that some differences in the maintenance of the language was observed among the two communities studied (Butalelbun y Cauñicu). Whereas, in Tirúa, language contact has left traces in the process of maintenance and language choice, since most families transmit only the official language to their children.
\end{abstract}

Keywords: Languages in contact, Mapudungun, intergenerational transmission, language.

Recibido: 23.01.2014. Aceptado: 01.08.2014.

\title{
1. INTRODUCCIÓN
}

iversos estudios que se han venido desarrollando en el último tiempo sobre la situación de la lengua mapuche en Chile proyectan un escenario bastante crítico para la continuidad de la lengua. Sostienen que su vitalidad estaría seriamente comprometida, pues se encuentra en una fase de retroceso, producto del avance progresivo del castellano. Este proceso de retracción se evidenciaría principalmente en la disminución del número de sus hablantes, en los bajos niveles de competencia, en la pérdida de ámbitos de uso tradicionales y en el quiebre de la transmisión intergeneracional (cf. Zúñiga, 2007; Durán, Catriquir y Hernández, 2007; Gundermann, Canihuan, Clavería y Faúndez, 2008, 2009; Lagos, 2012).

Sin embargo, esta situación sociolingüística está lejos de ser una realidad uniforme en toda la comunidad mapuche, puesto que el estado de la lengua en las diferentes comunidades y territorios manifiesta una considerable heterogeneidad (Gundermann et al., 2008, 2009). Esto se evidencia en las diferencias que presenta la lengua en las distintas regiones, en los segmentos poblacionales, en los hablantes urbanos y rurales, etc., incluso, se ha señalado que al interior de una misma región geográfica se pueden observar divergencias en el comportamiento lingüístico de 
los sujetos (cf. Vergara y Gundermann, 2005; Zúñiga, 2007; Gundermann et al., 2008, 2009; Wittig, 2009; Lagos, 2012).

En relación con el estado de la lengua en diferentes segmentos poblacionales, los estudios indican que la práctica regresiva del mapudungun no es extensiva a toda la población mapuche, ya que el grupo etario de los adultos y ancianos se releva como el más competente en la lengua originaria, mostrando las mejores cifras en la distribución del bilingüismo mapudungun-castellano (cf. Salas, 1992; Zúñiga, 2007; Durán et al., 2007; Gundermann et al., 2008, 2009). En cambio, la situación de las generaciones de niños y jóvenes es, en general, opuesta a la de los adultos y adultos mayores, ya que su grado de proficiencia estaría en declive ${ }^{1}$. Este grupo se caracterizaría no sólo por presentar los menores índices de bilingüismo, sino que, además, las habilidades lingüístico-comunicativas que logra alcanzar no le permite una producción lingüística desarrollada (Durán et al., 2007; Zúñiga, 2007; Gundermann et al., 2009).

En los diferentes territorios y regiones, la situación de la lengua es, como se señaló, bastante diversa: existen zonas donde el mapudungun está en estado crítico; otras, donde se conserva débilmente; y hay zonas que sobresalen por su mayor vitalidad, con un volumen mayor de hablantes.

Según los resultados de la encuesta sociolingüística aplicada a hogares mapuches del sur de Chile 2 , la Región de la Araucanía es la que presenta los mejores índices de bilingüismo, puesto que la mitad de las personas demuestra algún tipo de competencia en su lengua vernácula $(51,6 \%)$. Aquí se concentraría el mayor número de hablantes del sur de Chile. Sin embargo, como establecen algunos investigadores, no estaría exenta de problemas, pues en algunos sectores de esta región también se constatan procesos de desplazamiento lingüístico (Gundermann et al., 2008, 2009).

La Octava Región del Bío-Bío, de gran interés para nosotros porque en dos de sus comunas (Tirúa y Alto Bío-Bío) se llevó a cabo esta investigación, presenta un panorama sociolingüístico distinto al anterior, caracterizado por un claro contraste entre la zona costera lafkenche de Arauco y la zona cordillerana pewenche de Alto Bío-Bío. Éstas son las dos áreas que concentran la mayor cantidad de población mapuche de la Región ${ }^{3}$ (por ello es que fueron seleccionadas para este estudio). La primera, se caracteriza por presentar una situación bastante desfavorable para la lengua originaria, con niveles de bilingüismo muy escasos y concentrados en la

\footnotetext{
${ }^{1}$ Ya en el año 1984, Salas había advertido sobre esta situación cuando señalaba que "se ha detectado que parte de la población infantil y juvenil ya no habla mapudungun, sino solamente castellano mapuchizado" (1984: 12).

${ }^{2}$ Esta encuesta sociolingüística fue aplicada durante el año 2007 en tres regiones del centro-sur del país: VIII, IX y X regiones, las cuales, según los investigadores, concentran la mayoría de la población mapuche de Chile. Los resultados de esta aplicación fueron publicados en el Perfil sociolingüistico de comunidades mapuche de la VIII, IX y X Región (Gundermann et al., 2008).

${ }^{3}$ Según cifras entregadas por el censo del año 2002 (www.ine.cl).
} 
población adulta, mientras que la segunda, Alto Bío-Bío, muestra una situación de alta vitalidad lingüística con muchos hablantes competentes en todas las edades (Gunderman et al., 2008, 2009). Según estos autores, "desde un punto de vista histórico-cultural la zona pehuenche del Alto Bío-Bío puede considerarse como un bolsón o núcleo lingüístico relativamente aislado en la cordillera andina hasta hace algún tiempo" (2008: 20).

La retracción de la lengua originaria que se observa en la provincia de Arauco se debería a los procesos históricos que ha vivido su población y que le significaron una mayor conexión y, por ende, un contacto intenso y fluido con la población occidental; mientras que la zona de Alto Bío-Bío aún mantiene una alta vitalidad de la lengua, producto de situaciones geográficas e históricas distintas: el relativo aislamiento geográfico que mantenía hasta hace algunos años impedía un contacto fluido con el resto de la provincia y la región. Según Gundermann et al. (2008) "el aislamiento geográfico y la alta exposición parecen guardar una relación directa con la continuidad y el cambio lingüístico" (25).

Por nuestra parte, quisiéramos señalar que aunque reconocemos la relevancia de los factores sociopolíticos e históricos en la configuración actual del perfil sociolingüístico de las comunidades mapuches en estudio (Alto Bío-Bío y Tirúa), no ahondaremos en este tema, pues escapa a los objetivos de este trabajo establecer relaciones o analizar los datos observados en virtud de los procesos sociohistóricos que han vivido las comunidades.

Frente a este escenario crítico que presentan las investigaciones sobre el mapudungun en Chile, resulta imprescindible realizar estudios descriptivos, detallados y focalizados para examinar la situación actual de la lengua en comunidades mapuches y aportar con nuevos o más antecedentes a la discusión. El trabajo que presentamos se orienta en esta dirección, pues intenta describir el estado del mapudungun en comunidades lafkenches y pewenches, poniendo el foco en el análisis específico y en el contraste interno de cada sector; es decir, en la medida de lo posible, intentaremos relevar las principales similitudes y diferencias que presenta la situación de la lengua en las dos comunidades de Alto Bío-Bío y en las dos localidades de Tirúa. La descripción se realizará a través del análisis de algunas dimensiones sociolingüísticas, tales como: los hablantes de mapudungun en la comunidad, los niveles de competencia de los niños (escolares) y el estado de la transmisión de la lengua al interior de la familia.

Creemos que el análisis de estas dimensiones es relevante a la hora de realizar un acercamiento a la situación de la lengua, puesto que, según la teoría sobre el contacto, se cuentan entre los principales indicadores de vitalidad de una lengua minoritaria (cf. Appel y Muysken, 1996; Fasold, 1996; Zimmermann, 1999; Blas Arroyo, 2008). Además, estos factores juegan un rol relevante en la explicación del cambio lingüístico.

Cabe subrayar que conocer el comportamiento sociolingüístico de los niños y 
sus familias es hoy día una tarea fundamental, ya que son éstos quienes están más directamente implicados en la preservación de la lengua. Si los niños dejan de hablarla o presentan un nivel de competencia que les impide comunicarse, resultaría claro que la vitalidad del vernáculo estaría comprometida.

Para la presentación de este análisis nos basaremos fundamentalmente en los resultados obtenidos a través de un cuestionario sociolingüístico aplicado a todos los niños que conforman la muestra, los que serán complementados con los datos resultantes de las entrevistas sociolingüísticas focalizadas realizadas a los educadores tradicionales ${ }^{4}$ de los cuatro establecimientos educacionales en los que trabajamos. Además, cuando sea necesario, se incluirán en el análisis las observaciones in situ realizadas por la investigadora durante el desarrollo de su trabajo de campo (2010 y parte de 2011).

La inclusión de las entrevistas a los educadores tradicionales -que tienen entre sus responsabilidades la enseñanza del mapudungun- y las observaciones en terreno, nos permite evitar o minimizar las posibles dificultades que tiene el hecho de preguntar a los niños sobre su competencia lingüístico-comunicativa en mapudungun y la de sus familiares, pues existe el riesgo de sub o sobrevalorar dichas competencias.

\section{ANTECEDENTES TEÓRICOS}

\subsection{Contacto y desplazamiento lingüístico}

Existe bastante coincidencia entre los especialistas a la hora de definir el contacto de lenguas (cf. Weinreich, 1974; Silva-Corvalán, 2001; Moreno Fernández, 2005; Klee y Lynch, 2009). En general, se entiende que dos o más lenguas están en contacto si las dos se usan en una misma sociedad o comunidad, al menos en un sector de la población; es decir, cuando existe bilingüismo. Este último concepto, por su parte, hace referencia al proceso lingüístico mismo y puede ser definido como la práctica de usar dos lenguas por un mismo hablante, al que se denomina bilingüe (Weinreich, 1974; Silva-Corvalán, 2001). Pero el contacto de lenguas se distingue del bilingüismo por el grado de uso de las lenguas que hacen los hablantes. Las lenguas en contacto pueden conllevar o no bilingüismo, pero todo bilingüismo implica lenguas en contacto y, por consiguiente, culturas en contacto (Serrano, 2011: 295).

Las situaciones de contacto de lenguas que caracterizan a una comunidad se corresponden siempre y de forma inequívoca con situaciones sociales, sean éstas

\footnotetext{
${ }^{4}$ En este estudio usaremos indistintamente los nombres de asesor cultural y educador tradicional, porque los sujetos con los que trabajamos se autodefinen de las dos maneras.
} 
de carácter cultural, ideológico, político o simbólico. Es por eso que el resultado lingüístico del contacto hay que analizarlo en estrecha relación con los factores sociales que caracterizan al hablante y la comunidad de la que forman parte (Thomason y Kaufman, 1988; Silva-Corvalán, 2001; Serrano, 2011). Para los especialistas, los fenómenos de variación lingüística producto del contacto se explican tanto por factores estructurales como por factores extralingüísticos o sociolingüísticos, aunque, para algunos, estos últimos parecieran tener mayor preponderancia que los primeros (Thomason y Kaufman, 1988). Esto se debería a que la historia sociolingüística del individuo condiciona su habla de forma única, por lo que las diferencias individuales pueden ser mínimas, pero significativas incluso dentro de un grupo pequeño (Silva-Corvalán, 2001). En este sentido, el análisis de aspectos sociolingüísticos como: los hablantes de la lengua indígena en la comunidad, la transmisión de la lengua, los contextos de uso, entre otros factores, no sólo aportan al conocimiento del estado de la lengua sino a la explicación del cambio lingüístico por contacto.

Por otra parte, algunos autores consideran que el contacto de lenguas genera, en ocasiones, una situación conflictiva en la que dos sistemas lingüísticos compiten entre sí provocando el desplazamiento total o parcial de alguno de ellos. En estos casos cabría hablar no de diglosia, sino de la existencia de un verdadero conflicto lingüístico en la comunidad (Aracil, 1965; Blas Arroyo, 2008). El concepto de conflicto lingüístico surge en el análisis de las situaciones de desigualdad social entre las lenguas, lo que se relaciona más con el aspecto dinámico del contacto de las lenguas y no tanto con la supuesta estabilidad que sugieren las interpretaciones diglósicas. Desde esta perspectiva crítica, la expresión conflictos entre lenguas refleja más certeramente el tipo potencial de relación asimétrica que se evidencia entre hablantes de lenguas con historias y trayectorias diversas y desiguales, como sería el caso del contacto del mapudungun con el castellano en algunas comunidades, en donde a la lengua indígena le corresponde el rol de lengua minoritaria y minorizada, mientras que al castellano, el de lengua mayoritaria y dominante.

En ocasiones, el contacto de lenguas puede desencadenar una serie de procesos, tales como la sustitución o desplazamiento lingüístico, el mantenimiento o la aparición de nuevas variedades.

El desplazamiento se entiende, en términos generales, como la sustitución de una lengua por otra ${ }^{5}$. Esta situación ocurre cuando una comunidad adopta una nueva lengua o variedad y renuncia a la lengua o variedad que hasta entonces había utilizado (Fishman, 1982). Por lo tanto, decir que estamos en presencia de un proceso de desplazamiento equivale a señalar que los miembros de una comu-

\footnotetext{
${ }^{5}$ Por el contrario, cuando la comunidad decide colectivamente seguir empleando la lengua o lenguas que ha usado hasta entonces, se habla de conservación o mantenimiento (Fasold, 1996).
} 
nidad han optado por una nueva lengua ${ }^{6}$ para las situaciones y los ámbitos en los que antes se utilizaba otra. (Cf. Fasold, 1996; Appel y Muysken, 1996; Siguán, 2001; Blas Arroyo, 2008). Este desplazamiento es de carácter funcional y se manifiesta principalmente en su variante generacional (Zimmermann, 1999).

El resultado de este proceso de competencia entre las lenguas ("conflicto") generalmente se da en favor de la lengua de mayor prestigio. Sin embargo, una lengua minoritaria nunca es reemplazada de repente por la lengua mayoritaria, sino que el uso lingüístico se hace variable, es decir, ambas lenguas en contacto se usan en el mismo contexto social; después del estado de uso variable, el uso de la lengua minoritaria podría ser excluido (Appel y Muysken, 1996).

\subsection{La transmisión de la lengua en contextos de desplazamiento lingüístico}

Uno de los escenarios más habituales del desplazamiento lingüístico equivale al abandono de la lengua minoritaria en la transmisión generacional entre padres e hijos (Blas Arroyo, 2008).

Cuando una lengua deja de usarse en el seno familiar afecta directamente la transmisión intergeneracional. Este hecho repercute directamente en el desempeño lingüístico y comunicativo de las generaciones más jóvenes. Según Fasold: "Si verdaderamente se está dando un cambio de lengua, se verá reflejado en que los hablantes de más edad hablarán la lengua en decadencia en mayor medida que los hablantes más jóvenes" (1996: 324). Para este autor, una proporción sustancial de las personas de una sociedad, a lo largo de su propia vida, casi nunca abandona totalmente el empleo de una lengua para adoptar otra. En la mayor parte de los casos, lo que sucede es que una generación bilingüe sólo transmite a la siguiente una de sus lenguas. Dado que el cambio intergeneracional requiere que la generación de más edad sea bilingüe, la proporción de hablantes bilingües de una población constituye un "factor de riesgo" de que ocurra un cambio o desplazamiento de lengua y se abandone uno de los dos sistemas (Fasold, 1996).

En definitiva, la interrupción en la transmisión de una lengua al interior de una comunidad tiene como consecuencia no sólo la disminución de la masa crítica de sus hablantes, sino también de sus niveles de competencia, factores claves para la viabilidad de la lengua.

En resumen, la transmisión de la lengua minoritaria a las nuevas generaciones es un factor determinante en el proceso de mantenimiento o desplazamiento lingüístico y, por lo tanto, en el porvenir inmediato de la lengua.

\footnotetext{
${ }^{6}$ Para Hagège, algunos miembros de la comunidad renuncian a su lengua autóctona para adoptar la que es considerada más eficaz en el mercado de los valores lingüísticos, esto es, para hacer suya la lengua que es el medio de la promoción económica y del ascenso social (2002: 108).
} 


\section{LA INVESTIGACIÓN}

\subsection{Objetivo}

El presente trabajo tiene como objetivo describir el estado del mapudungun en comunidades pewenches y lafkenches de la Región del Bío-Bío. Específicamente analizaremos algunos elementos sociolingüísticos como los hablantes de mapudungun, los niveles de competencia, especialmente de los escolares, y el estado de la transmisión intergeneracional de la lengua.

\subsection{Metodología}

\subsubsection{Zonas de estudio}

Para la realización de este estudio seleccionamos cuatro comunidades o localidades mapuches rurales de la Región: Butalelbun y Cauñicu de la comuna cordillerana de Alto Bío-Bío y Primer Agua y Ranquilhue de la comuna costera de Tirúa. Ambas comunas se destacan por su alta concentración de población indígena en la región.

\subsubsection{Tirúa}

La localidad de Tirúa es una comuna costera de la Región del Bío-Bío, ubicada a $50 \mathrm{~km}$ al sur del Lago Lanalhue, en el extremo sur de la Provincia de Arauco y al norte de la Provincia de Cautín, de la Región de la Araucanía. Esta comuna lafkenche se encuentra a $212 \mathrm{~km}$ de la ciudad de Concepción, capital regional, y a $127 \mathrm{~km}$ de Temuco. Su capital comunal se ubica en la desembocadura del río Tirúa, frente a la isla Mocha, a 38 $28^{\prime}$ de latitud sur y a $73^{\circ} 30^{\prime}$ de longitud oeste. La comuna de Tirúa tiene una población total aproximada de 10.000 habitantes, en una superficie de $624,4 \mathrm{~km}^{2}$, y con una densidad de población de 17,5 hab. I $\mathrm{km}^{27}$. Aproximadamente, el $70 \%$ de su población es de origen mapuche.

\subsubsection{Alto Bío-Bío}

Alto Bío-Bío es una comuna cordillerana de la Provincia de Bío-Bío, Octava Región, creada por la Ley 19.959, el año 2004. Se ubica a $220 \mathrm{~km}$ de Concepción, capital regional. Comprende una superficie de $2.098 \mathrm{~km}^{2}$, que se distribuyen en el área geográfica de la Cordillera Andina de la Región del Bío-Bío. Se extiende desde

${ }^{7}$ En Plan de Desarrollo Comunal (PLADECO), Tirúa, 2009. 
la confluencia de los ríos Queuco y Bío-Bío, teniendo como límite natural el río Queuco por el lado norte y oeste, a la provincia de Malleco por el sur, y al límite de la República de Argentina por el este.

Esta zona está habitada principalmente por comunidades pewenches, instaladas a lo largo de los valles de los ríos Queuco y Bío-Bío, hasta la frontera con Argentina. La población comunal corresponde a 7.027 habitantes, aproximadamente ${ }^{8}$, de los cuales un $80 \%$ son pewenches.

\subsubsection{Los participantes}

Para el logro de los objetivos propuestos trabajamos con una muestra selectiva e intencionada (Hernández y Almeida, 2005) de 40 escolares que cumplían con el siguiente perfil: (1) ser miembro de alguna comunidad pewenche o lafkenche; (2) autodefinirse como mapuche o que al menos uno de sus progenitores perteneciera a la etnia mapuche; (3) tener entre 12 y 15 años; (4) pertenecer a un establecimiento educacional adscrito al PEIB y estar cursando $7^{\circ}$ u $8^{\circ}$ año básico.

El número de niños que formó parte de la muestra, así como las localidades y escuelas seleccionadas, fue un proceso que se fue configurando a medida que desarrollamos el trabajo de campo, pues dependió de factores empíricos relacionados con la realidad lingüística de cada comunidad y/o escuela consultada. Para la configuración de la muestra nos guiamos por un principio rector: se buscó aquellas escuelas y localidades que distintos agentes (comuneros, docentes, directivos, funcionarios del Departamento de Educación y Cultura de la Corporación Nacional de Desarrollo Indígena (CONADI), coordinadores municipales del PEIB, funcionarios de la $\mathrm{Di}$ rección de Administración de Educación Municipal (DAEM), etc., nos señalaron como zonas de mayor retención del vernáculo (donde "más se habla la lengua").

De este modo, se seleccionaron 4 establecimientos educacionales adscritos al PEIB: dos de la comuna de Tirúa (escuela de Primer Agua y escuela de Ranquilhue) y dos de Alto Bío-Bío (escuela de Cauñicu y escuela de Butalelbun). Del total de escolares que formó parte de esta muestra, 20 pertenecían a Tirúa y 20 a Alto Bío-Bío.

Además de los escolares, esta muestra estuvo compuesta por cuatro informantes expertos (Hernández, Fernández y Baptista, 2003). Nos referimos a los educadores tradicionales ${ }^{9}$ o asesores culturales de cada establecimiento educacional

\footnotetext{
${ }^{8}$ Plan de Desarrollo Comunal (PLADECO), Alto Bío-Bío, 2006.

${ }^{9}$ El educador tradicional, debido a su alta competencia en mapudungun y al conocimiento de las prácticas socioculturales y lingüísticas de los escolares y sus familias, es quien pone en práctica el proceso de enseñanza de la lengua indígena, junto al profesor mentor. Es necesario precisar que la figura del educador tradicional aparece con la entrada en vigencia del nuevo subsector de Lengua Indígena en el curriculum escolar de enseñanza básica (2010). Esta figura es heredera del asesor cultural, es decir, los antiguos asesores culturales son ahora los educadores tradicionales de las escuelas insertas en el PEIB.
} 
seleccionado, quienes tuvieron un rol complementario en esta investigación, pues a través de entrevistas sociolingüísticas focalizadas nos aportaron información sociolingüística de relevancia sobre las familias y la comunidad en general.

\subsubsection{Procedimientos o estrategias de recolección de la información}

Para la elicitación del material aplicamos un cuestionario sociolingüístico a los escolares, el cual estaba compuesto por preguntas cerradas y abiertas. Su objetivo fue recoger la mayor cantidad de información sociolingüística sobre los escolares y sus familias.

Se realizó, además, una entrevista a los educadores tradicionales de cada escuela, en su condición de expertos o actores relevantes del fenómeno sociolingüístico en estudio. Su propósito fue recoger información sociolingüística sobre el estado de la lengua indígena en la familia y en la comunidad. La información recogida nos permitió complementar y corroborar los datos entregados por los escolares.

Se aplica, además, la observación etnográfica para conocer con más detalle las prácticas sociolingüísticas de la comunidad de habla. En efecto, de la relación cotidiana que se crea con los sujetos surgen indicios y respuestas preliminares que complementan los datos obtenidos por medio de las otras técnicas sociolingüísticas.

\subsubsection{Trabajo de Campo}

El trabajo de campo se realizó durante el año 2010 y el primer semestre del año 2011. Durante este período ${ }^{10}$ realizamos numerosos viajes a las respectivas comunidades y escuelas para la aplicación de los cuestionarios y entrevistas. Cada visita a la comunidad escolar tuvo una duración de dos a tres días aproximadamente.

Durante nuestros viajes y permanencia en las escuelas-internados de las cuatro localidades, tuvimos la oportunidad de conocer y conversar con diferentes miembros de cada comunidad mapuche, desde autoridades (longkos), hasta padres y apoderados de los niños encuestados. Del mismo modo, tuvimos la ocasión de compartir largamente durante cada visita con los(as) profesores(as) de cada escuela y con los(as) directores(as) o docentes directivos. Todos ellos nos aportaron valiosos antecedentes sobre las familias de los niños, la comunidad en general y sobre el estado de la lengua en particular.

\footnotetext{
${ }^{10}$ Durante el trabajo de campo realizamos aproximadamente 26 visitas o viajes a las escuelas de las respectivas comunidades. Esto porque, además de la información sociolingüística, recogimos datos fonético-fonológicos de cada una de las comunidades seleccionadas para describir el estado de la fonología segmental de cada zona en estudio (Henríquez y Salamanca, 2012; Henríquez, 2013).
} 


\section{RESULTADOS}

\subsection{Los hablantes de mapudungun en la comunidad}

A continuación se presentarán los resultados obtenidos en relación con los hablantes de mapudungun en cada comunidad, es decir, quiénes hablan la lengua hoy en día y quiénes serían, a juicio de nuestros colaboradores, los hablantes más competentes en mapudungun al interior de las familias. Del mismo modo, presentaremos los resultados sobre el nivel de competencia en mapudungun que declaran poseer los estudiantes.

En este sentido, una primera pregunta que realizamos a los escolares fue: ¿Quiénes hablan chedungun/mapudungun en tu familia? Las opciones de respuestas fueron: Papá, Mamá, Abuelos(as), Tíos(as), Hermanos(as), Primos(as), Otros(as). En el Gráfico 1 se presentan los resultados para cada localidad.

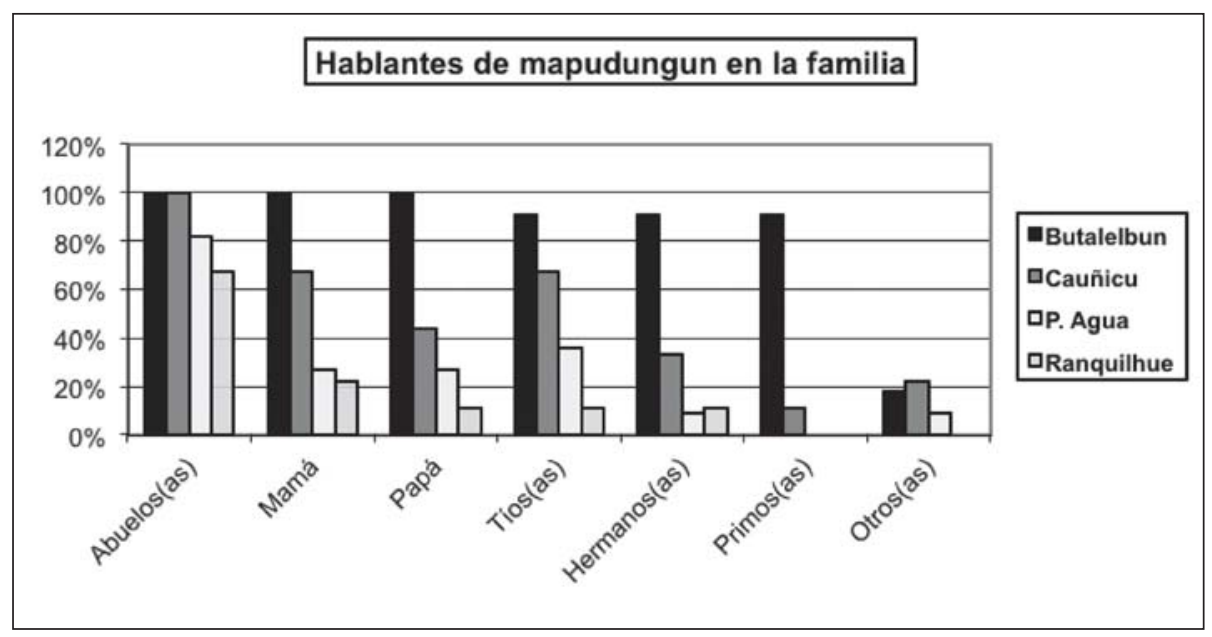

Gráfico 1. Los hablantes de mapudungun en la familia (Alto Bío-Bío y Tirúa).

Como se puede observar, la comunidad de Butalelbun es por lejos la mejor posicionada en cuanto al porcentaje de hablantes de mapudungun al interior de la familia. En efecto, según los escolares, la gran mayoría de sus familiares son hablantes, aunque el segmento de los adultos concentra el mayor porcentaje. Según lo declarado, los(as) abuelos(as) y progenitores de los escolares son todos hablantes de mapudungun (100\%). El resto de los integrantes de la familia (hermanos(as), tíos(as) y primos(as)) también son hablantes en más de un $90 \%$ de los casos. 
En Cauñicu, la situación es diferente, pues es entre los(as) abuelos(as) donde encontramos el mayor número de hablantes (100\%), seguidos por los adultos: mamá (67\%), tíos(as) (67\%) y papá (44\%). El resto de los integrantes de la familia presenta los menores índices: hermanos(as), con un 33\%; y primos(as), con un $11 \%$. Los hablantes al interior de la familia disminuyen, a medida que disminuye el rango etario de los sujetos.

Es interesante observar la diferencia que existe entre la comunidad de Butalelbun y Cauñicu, geográficamente muy próximas al interior del valle del río Queuco. Sólo coinciden en el segmento de los adultos mayores o abuelos, al presentar similares porcentajes de hablantes; sin embargo, las diferencias se acentúan de manera considerable si nos centramos en la franja etaria más joven (primos(as) y hermanos(as)). Esto implica, como veremos más adelante, que mientras en Butalelbun las familias continúan enseñando ambas lenguas, en Cauñicu este patrón de transmisión no se da igual en todas las familias.

En Tirúa, los hablantes de mapudungun al interior de la familia se ubican muy por debajo de las cifras observadas en Alto Bío-Bío. Así, por ejemplo, la mayor concentración de hablantes se encuentra en el grupo de los(as) abuelos(as), tanto en Primer Agua (82\%) como en Ranquilhue (67\%). Por otra parte, los progenitores de los escolares son, en su mayoría, monolingües de castellano. En primer Agua, sólo el 27\% de los padres y madres son hablantes, mientras que en Ranquilhue esta situación es más preocupante, pues sólo alcanza el 22\% de las madres y apenas un $11 \%$ de los padres. En relación con las generaciones más jóvenes, la situación es aún más crítica, porque el número de hablantes es mínimo, como en el caso de los(as) hermanos(as), o inexistente, como en el caso de los(as) primos(as). En Primer Agua, sólo un escolar declaró tener un hermano hablante, mientras que en Ranquilhue fueron dos.

Otro aspecto que se debe tener presente es que estas cifras sólo nos informan sobre la existencia o no de hablantes de mapudungun al interior de las familias, pero no sobre el nivel o grado de competencia que tienen estos sujetos para desempeñarse en esta lengua. Esta es una situación compleja y heterogénea que merece ser investigada en profundidad.

Para confirmar y complementar los datos anteriores, consultamos a los niños por los hablantes de mapudungun más competentes de su comunidad. Para ello agrupamos a los posibles hablantes en cuatro segmentos generacionales. Específicamente, preguntamos: ¿Quién crees tú que habla mejor la lengua mapuche en tu comunidad? Las opciones de respuestas eran: Ancianos(as), Adultos (padres, madres, tíos), Jóvenes y Niños. Como queríamos acercarnos a los niveles de producción y comprensión en mapudungun de cada grupo, les solicitamos a los escolares que calificaran a estos hablantes, asignándoles un puntaje según una escala de 0 a 7. 
La escala de calificación fue la siguiente:

0: No habla ni entiende

1: Entiende un poco, pero no habla

2. Entiende bastante, pero no habla

3: Entiende todo, pero no habla
4: Habla un poco y entiende un poco

5: Habla sólo un poco, pero entiende todo

6: Habla bastante y entiende todo

7: Habla muy bien y entiende todo

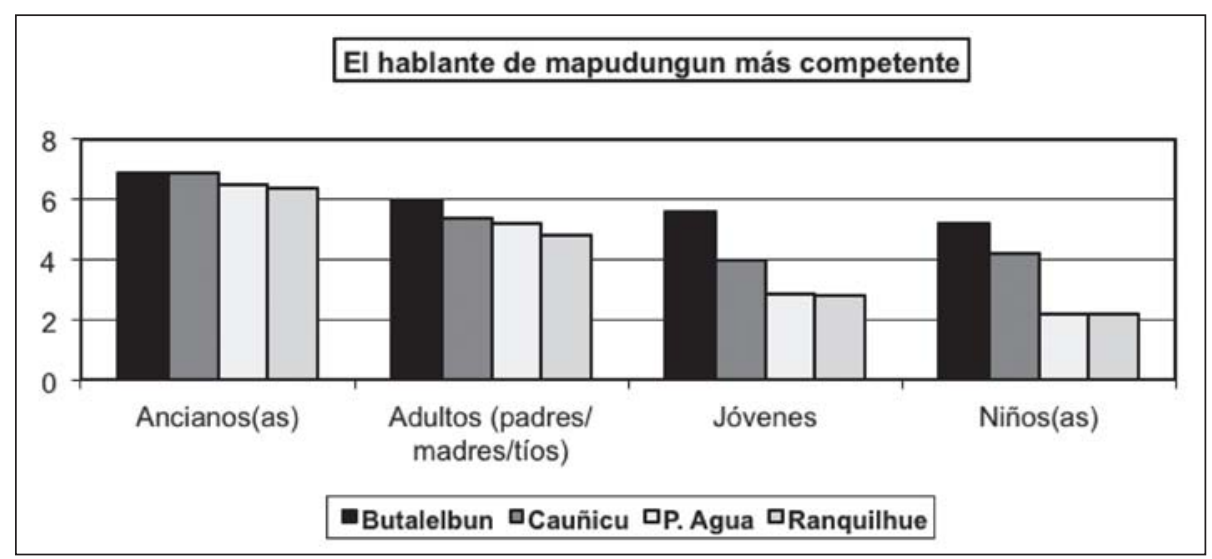

Gráfico 2. Niveles de competencia en mapudungun por grupo etario.

Las respuestas que nos dan los escolares son coherentes con la información entregada en la pregunta anterior. El segmento de los ancianos o adultos mayores (abuelos), donde según se dijo se concentra el mayor número de hablantes en las familias, es además el que obtiene la mejor calificación de desempeño en las cuatro comunidades; es decir, son los mejores hablantes de mapudungun en la comunidad.

$\mathrm{Al}$ analizar la información por comunidades, resulta evidente que los hablantes de Butalelbun alcanzan las mayores puntuaciones de desempeño en los diferentes grupos generacionales, lo que implica que es la comunidad con mayor vitalidad, seguida a cierta distancia por Cauñicu, donde se confirma que el grupo de los ancianos presenta similares competencias a las del mismo segmento de Butalelbun; sin embargo, a partir del grupo de adultos (padres, madres y tíos) empieza a profundizarse la diferencia en los niveles de comprensión y producción en la lengua originaria, la que se acentúa aún más para el caso de las generaciones más jóvenes (jóvenes y niños). Esto significa que la mayoría de los grupos generacionales de 
Cauñicu, excluyendo a los ancianos, muestran menores competencias en la lengua tradicional que sus vecinos de Butalelbun.

Este cuadro de competencia por segmento generacional se completa con las comunidades lafkenches de Tirúa, cuyos hablantes, en los diferentes grupos etarios, obtienen las más bajas puntuaciones de desempeño. Ahora, si el análisis se realiza comparando ambas localidades, se puede advertir que Primer Agua presenta índices de desempeño levemente superiores a los de Ranquilhue, con excepción del grupo de los niños, cuya puntuación es similar en ambos sectores, ubicándose en la categoría 2 de la escala ("Entiende bastante pero no habla"). Con respecto a este grupo, nos parece importante relevar los bajos niveles de desempeño en mapudungun que presenta, según la evaluación de sus propios pares. Poseen ciertas competencias receptivas en la lengua mapuche, pero carecen de competencias productivas, es decir, no hablan la lengua.

En definitiva, el panorama general que muestran las respuestas de los escolares podría resumirse en que los niveles de comprensión y producción en mapudungun -es decir, el manejo general de la lengua- se van debilitando conforme disminuye la edad de los hablantes. Esto es extensivo a las cuatro comunidades, pero a diferente escala. Sin duda, son las comunidades de Primer Agua y Ranquilhue las que presentan la distribución de desempeño por edad más crítica para el futuro de la lengua en el sector.

\subsection{Competencia en mapudungun de los escolares}

La tercera y cuarta pregunta que realizamos a los niños apuntaba a conocer la estimación de su propio dominio de la lengua tradicional. Así, en primer lugar les consultamos por su conocimiento general de la lengua mapuche y, luego, para profundizar un poco más, indagamos en su nivel de comprensión y producción. Concretamente, les preguntamos: ¿Hablas la lengua mapuche? Las alternativas de respuesta fueron tres: Sí, No, Sólo un poco.

El Gráfico 3 muestra los resultados de las respuestas de los escolares de las cuatro localidades. Nuevamente, Alto Bío-Bío, especialmente Butalelbun, muestra los mejores índices, con un 100\% de los niños que se declaran hablantes de la lengua minoritaria. Esta situación no se replica en ninguna de las otras localidades. 


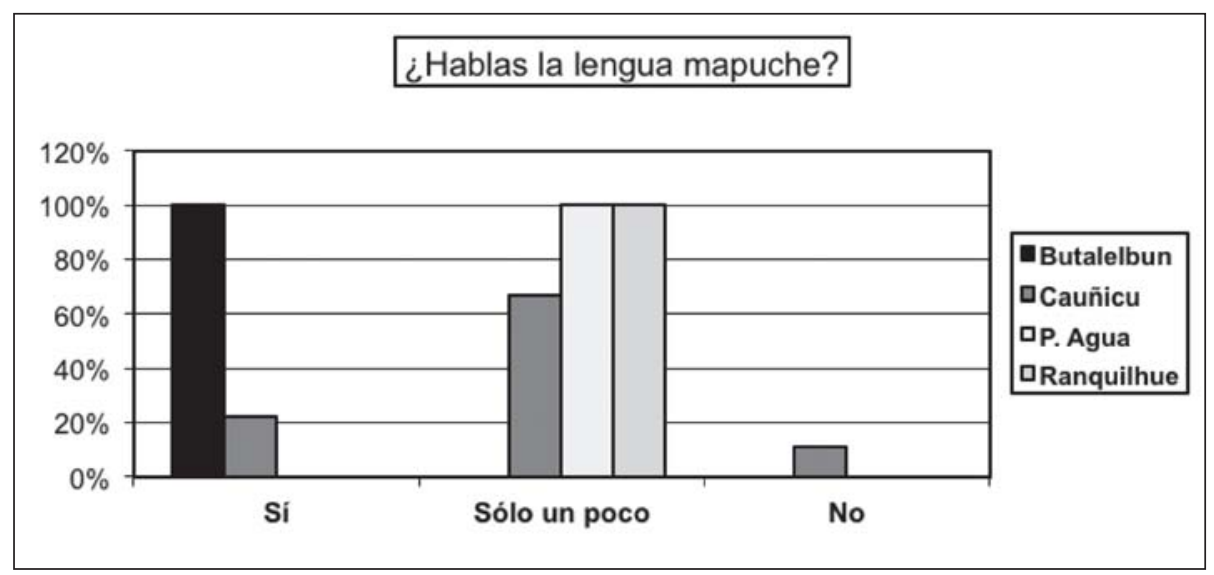

Gráfico 3. Los escolares y su declaración de competencia en mapudungun (Alto Bío-Bío y Tirúa).

En Cauñicu se observa una situación más dispersa o heterogénea, pues la mayoría de los escolares (67\%) declara hablar la lengua tradicional "Sólo un poco", mientras que aquellos que " $S$ " la hablan son los menos (22\%). En el otro extremo, un estudiante señala " $N o$ " hablarla, pero como se verá en el análisis de la pregunta siguiente, todos los escolares de este sector declaran poseer ciertas competencias receptivas o de comprensión; es decir, este estudiante no habla la lengua, pero sí entiende "un poco" ("bilingüe pasivo").

En Tirúa, en tanto, la situación es más homogénea, pero más desfavorable para el mapudungun, ya que los escolares de Primer Agua y Ranquilhue se ubican en su totalidad en la categoría "Sólo un poco". Es decir, declaran tener ciertos conocimientos en la lengua tradicional. Sin embargo, debido al carácter general de esta categoría se hace necesario profundizar un poco más en este grado de dominio. Por ello les consultamos por sus niveles de producción y comprensión en mapudungun. Específicamente, les solicitamos que se autocalificaran, según su competencia, en una escala de 0 a 7 (similar a la escala de la pregunta 2):

0: No hablo ni entiendo

1: Entiendo un poco, pero no hablo

2. Entiendo bastante, pero no hablo

3: Entiendo todo, pero no hablo
4: Hablo un poco y entiendo un poco

5: Hablo sólo un poco, pero entiendo todo

6: Hablo bastante y entiendo todo

7: Hablo muy bien y entiendo todo 
La información entregada por los escolares (Figura 1) permite advertir un continuo de desempeño en mapudungun: en un extremo (izquierdo) se ubican los escolares de Tirúa, tanto de Ranquilhue como de Primer Agua, quienes declaran poseer menor competencia en el vernáculo, adscribiéndose entre los niveles 1 al 4; mientras que en el otro extremo (derecho) se sitúan los niños de Butalelbun, mucho más competentes en la lengua originaria (5-7). Los estudiantes de Cauñi$\mathrm{cu}$, por otra parte, muestran una diversidad de desempeños, por lo que se ubican a lo largo del continuo (1-7). Esta situación se puede representar de la siguiente manera:

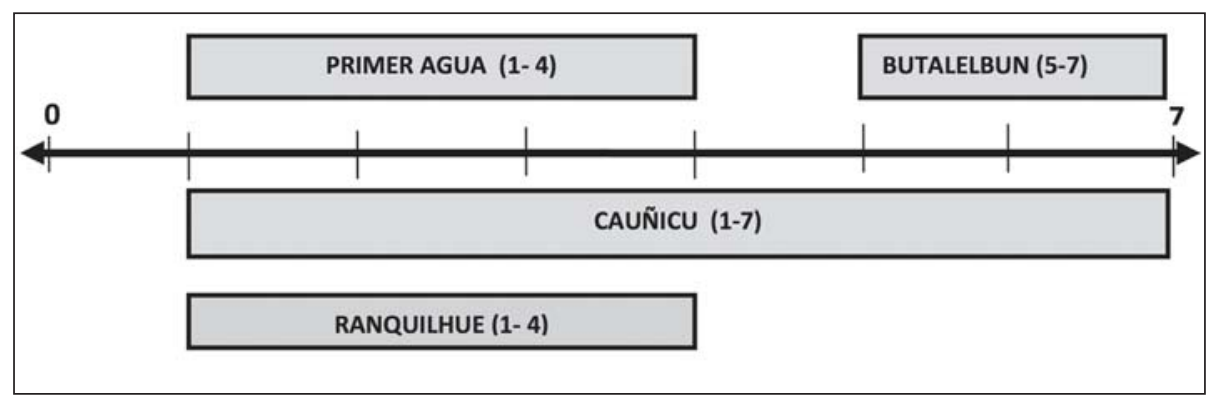

Figura 1. Conocimiento del mapudungun: autoevaluación de los escolares

(Alto Bío-Bío y Tirúa).

En Cauñicu, ciertamente, se observa una distribución del desempeño muy heterogénea; sin embargo, es necesario precisar que la mayoría de los estudiantes (77\%) se autoadscribe entre las categorías 4-5, es decir, declaran poseer escasa o baja competencia productiva, pero altos niveles de comprensión. En los extremos del continuo sólo se ubican dos niños del sector: uno en el extremo positivo (7) y otro, en el negativo (1). Ninguno se autoadscribe en la categoría 0 (No hablo ni entiendo).

En Butalelbun, en cambio, la mayoría de nuestros encuestados se autocalifican entre las categorías 6-7 (81\%), manifestando, una vez más, que son los más competentes en mapudungun de toda nuestra muestra. Creemos, eso sí, que de todo el grupo, estos escolares son los más críticos o autoexigentes en su autoevaluación, lo que se podría explicar, de algún modo, por la existencia de un nivel de conciencia lingüística o de la norma (Fishman, 1982; Siguán, 2001) mucho más desarrollada que en el resto de los escolares, precisamente, porque se desempeñan en un contexto (comunidad) altamente competente en la lengua originaria y, en consecuencia, de alta vitalidad ${ }^{11}$.

${ }^{11}$ Nosotros, por ejemplo, luego de triangular toda la información recogida a lo largo de nuestro 
Otra es la situación que se observa en Tirúa, donde la categoría 4 ("Hablo un poco y entiendo un poco") concentra a la mayoría de los escolares de Primer Agua (90\%) y de Ranquilhue (77\%). Esta autocalificación de competencia es coherente con las respuestas obtenidas en la pregunta anterior, cuando todos ellos declararon hablar "Sólo un poco" la lengua originaria. Sin embargo, creemos que no todos los niños que se autoadscriben en esta categoría (4) poseen el mismo nivel de comprensión y producción. Según lo observado en terreno, la mayoría de ellos posee algunas competencias receptivas o de comprensión, pero carecen de las competencias productivas mínimas que les permitan comunicarse. Pensamos que este "Hablo un poco y entiendo un poco" implica, básicamente, y en la mayoría de los casos, el conocimiento de un conjunto de vocabulario de uso cotidiano y de algunas fórmulas lingüísticas de uso frecuente, principalmente imperativas (órdenes, mandatos), que ocurren en las interacciones entre abuelos y niños en el ámbito doméstico. Esta situación es corroborada, como se verá más adelante, por las afirmaciones que realizan los educadores tradicionales de la zona.

En conclusión, según este esquema general de desempeño comunicativo, es lógico suponer que el uso frecuente del mapudungun entre los niños ocurre principalmente en Butalelbun, mientras que en ambas localidades de Tirúa esta lengua cede el paso al castellano en las interacciones comunicativas, debido a la escasa competencia productiva que poseen. En Cauñicu, en cambio, alternan ambos tipos de comportamientos comunicativos.

Para finalizar el análisis de esta dimensión, presentaremos algunas declaraciones efectuadas por los educadores tradicionales de las cuatro comunidades en estudio, las cuales corroboran y complementan la información sociolingüística entregada por los escolares.

\begin{tabular}{|l|l|}
\hline Declaración Asesor cultural o Educador tradicional & Localidad \\
\hline $\begin{array}{l}\text { "Los niños desde chico hablan su lengua y ellos no tienen ningún } \\
\text { problema de hablar. Aquí, [Butalelbun] } 100 \% \text { están hablando los } \\
\text { niños". }\end{array}$ & Butalelbun \\
\hline $\begin{array}{l}\text { "De la comunidad de Malla Malla para abajo ya están perdiendo su } \\
\text { lengua. Cauñicu también están perdiendo su lengua". }\end{array}$ & Butalelbun \\
\hline $\begin{array}{l}\text { "Aquí [Cauñicu] hay varios niños que hablan chedungun. En } 7^{\circ} \text { y } 8^{\circ} \\
\text { hay como } 3 \text { ó } 4 \text { niñas que hablan perfectamente el chedungun, los } \\
\text { demás de entender entienden, pero de hablarlo..... }\end{array}$ & Cauñicu \\
\hline
\end{tabular}

trabajo de campo, habríamos calificado a todos estos niños, sin excepción, en la categoría 7 ("Hablo muy bien y entiendo todo"). 
Continuación Tabla.

\begin{tabular}{|c|c|}
\hline $\begin{array}{l}\text { "[Los mejores hablantes] yo creo que son las personas mayores, todos } \\
\text { los de arriba de } 50 \text { años la mayoría hablan chedungun, por lo que } \\
\text { yo he visto. En las reuniones la gente que opinaba era gente mayor } \\
\text { de } 50 \text { años, opinaba en puro chedungun. Los adultos y los ancianos, } \\
\text { pero yo creo que de los treinta hacia abajo ya hay un problema”. }\end{array}$ & Cauñicu \\
\hline $\begin{array}{l}\text { "Las personas que hablan son pocos y eso se les ha complicado a estos } \\
\text { ancianos porque tienen el problema". }\end{array}$ & Primer Agua \\
\hline $\begin{array}{l}\text { "Aquí, [los niños de la escuela] todos entienden algo, palabritas, pero } \\
\text { no pueden todavía dar siquiera un poquito de palabra como tipo } \\
\text { conversa, ninguno pueden todavía conversar". }\end{array}$ & Primer Agua \\
\hline $\begin{array}{l}\text { "Los mejores hablantes de chedungun son las machis y los más anti- } \\
\text { guos. Los de 60, 70, } 80 \text { y } 90 \text { años". }\end{array}$ & Ranquilhue \\
\hline $\begin{array}{l}\text { "En la escuela no hay ningún niño que hable o pueda conversar en } \\
\text { mapudungun". }\end{array}$ & Ranquilhue \\
\hline
\end{tabular}

En primer lugar, nuestros entrevistados confirman que la comunidad de $\mathrm{Bu}-$ talelbun es la más vital en cuanto al conocimiento de la lengua que tienen los hablantes en las diferentes franjas etarias, incluso entre los niños. En Cauñicu, en cambio, no todos los integrantes del grupo familiar hablan la lengua mapuche. Los educadores tradicionales de la zona, corroborando lo declarado por los escolares, señalan que el chedungun está en manos de los ancianos(as) y adultos (padres y madres); además, aunque reconocen que aún existe un grupo de jóvenes y niños que habla la lengua en el sector, declaran que muchos jóvenes y niños de Cauñicu estarían reemplazando la lengua por el castellano.

La disminución de hablantes jóvenes e infantiles en Cauñicu tiene consecuencias negativas para el futuro de la lengua, pues, como se señala en la literatura especializada, la existencia en el entorno del usuario bilingüe de otros hablantes de la lengua minoritaria pertenecientes al mismo grupo etario es un factor relevante en el mantenimiento lingüístico ${ }^{12}$.

De acuerdo con las coordenadas propuestas por autores como Fasold (1996) y

\footnotetext{
${ }^{12}$ Una estudiante de Cauñicu, la más competente en chedungun del grupo, nos contó que para ella era difícil hablar la lengua en la escuela, porque la mayoría de sus compañeros, aunque entendían un poco, no hablaban y los que sí hablaban, no querían hacerlo. El educador tradicional era, principalmente, su interlocutor.
} 
Blas Arroyo (2008), lo que sucede en Cauñicu es un indicio de cambio o desplazamiento en marcha, que se refleja en el hecho de que los hablantes de más edad hablan la lengua minoritaria o amenazada en mayor medida que los hablantes más jóvenes.

Por último, con respecto a las localidades de Tirúa, los entrevistados confirman que los ancianos o adultos mayores son los más conservadores, pues son los principales hablantes de chedungun, aunque también existirían algunos adultos (progenitores de los escolares) hablantes en las familias. El segmento de los jóvenes y niños prácticamente ha abandonado la lengua, lo que permite sostener la existencia de un proceso de desplazamiento lingüístico en la zona mucho más avanzado que en Cauñicu. Este patrón sugiere que, a medida que pasa el tiempo, el castellano se está imponiendo en desmedro del chedungun.

Por último, quisiéramos acotar que en contextos de desplazamiento lingüístico de una lengua minoritaria surgen dificultades para definir y segmentar los diferentes perfiles de hablantes que se observan (esto nos sucedió en Cauñicu y, principalmente, en Tirúa). En este sentido consideramos necesario flexibilizar y ampliar la taxonomía de hablantes para abarcar todos los comportamientos lingüísticos de los sujetos de una comunidad de habla en retracción (Dorian, 1977; Nercesian, 2007).

\subsection{Transmisión del mapudungun en la comunidad}

Como se señaló anteriormente, el factor generacional es una de las variables sociales de mayor relevancia en los procesos de mantenimiento o desplazamiento lingüístico (Fasold, 1996; Appel y Muysken, 1996; Siguán, 2001; Blas Arroyo, 2008). En este último caso, el quiebre en la transmisión intergeneracional de la lengua entre padres e hijos restringe la vitalidad de ésta, por cuanto impacta directamente en la masa crítica de hablantes, factor clave en la pervivencia de la lengua a través del tiempo. Por ello la relevancia de incluir el análisis de esta dimensión en esta presentación.

Para abordar el estado de los procesos de transmisión del mapudungun entre padres e hijos en las comunidades, se realizó la siguiente pregunta a los estudiantes: “¿Quién o quiénes te enseñaron la lengua mapuche?". Las opciones de respuesta fueron: Padre; Madre, Abuelos(as) y Educador o Asesor tradicional. Los resultados se presentan en el siguiente gráfico. 


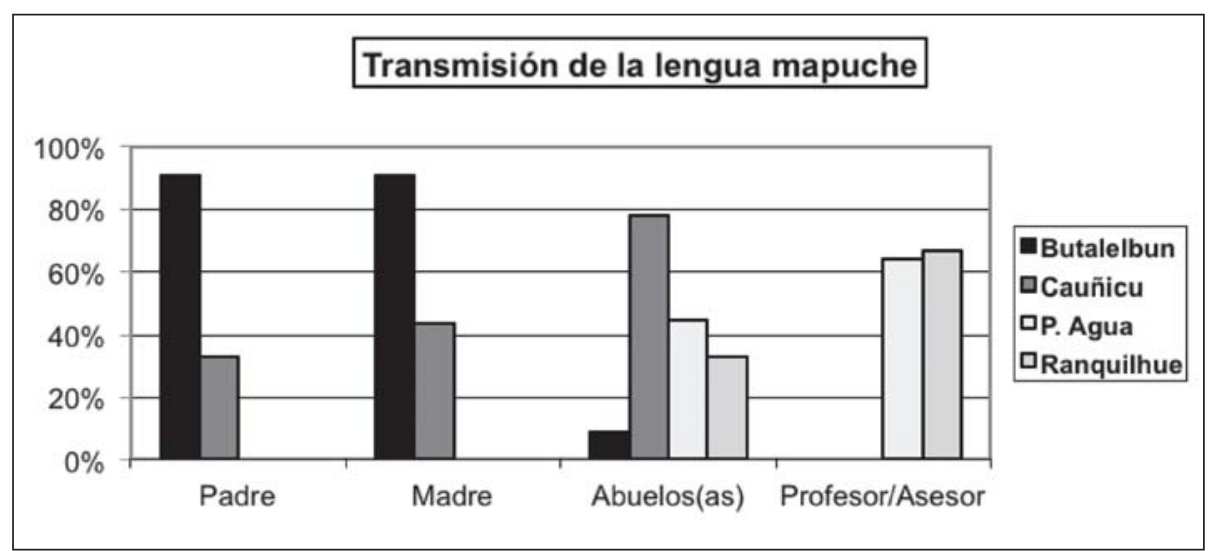

Gráfico 4.Transmisión de la lengua mapuche en Alto Bío-Bío y Tirúa.

Como se aprecia en el Gráfico 4, diferentes son los agentes que cumplen el rol de transmitir la lengua vernácula a los niños. Su elección depende de la comunidad a la que se pertenezca. Así, en Butalelbun se observa con claridad que son los progenitores (padre-madre) quienes fundamentalmente cumplen con este papel (91\%). Los(as) abuelos(as) prácticamente no intervienen en este proceso (9\%). Estos datos sugieren que la transmisión de la lengua se realiza "de manera natural" en el seno familiar, como ocurre en el caso de la mayoría de las comunidades lingüísticas cuyas lenguas gozan de buena salud. En otras palabras, el rol de transmisión de la lengua está intacto en esta comunidad; hoy en día los padres no transmiten sólo la lengua de prestigio, sino que también enseñan la lengua indígena, motivo por el cual los niños crecen aprendiendo y usando ambas lenguas.

En Cauñicu, en cambio, los(as) abuelos(as) son quienes, principalmente, cumplen con esta labor de transmisión (78\%), mientras que los progenitores (padre, $33 \%$, y madre, 44\%) quedan relegados a un segundo plano. Estos datos evidencian cierto quiebre en la transmisión al interior de la familia: algunos padres transmiten ambas lenguas a sus hijos, pero, principalmente, les enseñan el castellano, porque no conocen bien la lengua minoritaria o bien porque han decidido no enseñarla ${ }^{13}$, provocando con esto un cambio en el patrón tradicional (natural) de transmisión y la consecuente disminución del número de hablantes en el segmento más joven.

${ }^{13}$ Es necesario consignar que de este grupo, sólo una estudiante vivía con su abuelo, el resto de los niños convivía con ambos padres o, al menos, con uno de ellos. Esta escolar fue la única que se autoevaluó con una puntuación 7, es decir, en la categoría "Hablo muy bien y entiendo todo", lo que fue corroborado por el educador tradicional, quien la calificó como la mejor hablante de chedungun de $8^{\circ}$ año. Este es un indicador del rol que tienen los abuelos en la enseñanza de la lengua, puesto que están entre los hablantes más competentes y, por lo mismo, entre los más capacitados para cumplir con la transmisión. 
En Primer Agua y Ranquilhue, los escolares nos señalan que la enseñanza de la lengua indígena es compartida tanto por los(as) abuelos(as) (45 y 33\%, respectivamente) como por el educador tradicional (64 y 67\%, respectivamente), lo que indica que la transmisión de la lengua estaría en manos, principalmente, de agentes que no forman parte del núcleo familiar. Destacamos que, en ambas localidades, la totalidad de los niños (100\%) no menciona a sus padres (madre y padre) en este rol de transmisión, lo que se traduce en un quiebre total del traspaso de la lengua entre padres e hijos.

Esta dinámica de interrupción se entiende en el contexto de la inexistencia de padres o madres hablantes de mapudungun, lo que pareciera ser lo más común entre las familias lafkenches; sin embargo, sabemos de la existencia de algunos progenitores hablantes que han optado por no transmitir la lengua ancestral y practican con sus hijos sólo la lengua oficial ${ }^{14}$. Esta situación es relevante por las implicancias que tiene para el futuro del mapudungun en estas localidades; por lo mismo, creemos que amerita un estudio sociolingüístico en profundidad, pues, como algunos investigadores han señalado, si no se retoma la enseñanza informal del mapudungun al interior de las familias, cualquier programa oficial de recuperación o revitalización podría estar destinado al fracaso (Zúñiga, 2007) ${ }^{15}$.

Otro aspecto que llama la atención en esta zona y que está relacionado con el punto anterior, es el rol preponderante que le asignan los niños al educador tradicional de su escuela como agente de transmisión de la lengua, desplazando en esta labor a los miembros de la familia. Con esto se confirma que la enseñanza del mapudungun se ha transferido desde la familia a la escuela. Sin embargo, pareciera ser que este proceso de enseñanza o revitalización de la lengua que se ha impuesto la escuela, a través de su Programa de Educación Intercultural Bilingüe (PEIB) no ha dado los frutos esperados, pese a que el Programa tiene una data de más de 8 años de existencia en la zona ${ }^{16}$. Prueba de ello son los bajos niveles de desempeño

\footnotetext{
${ }^{14}$ Conocimos en Primer Agua a una mujer hablante de mapudungun (su primera lengua) y madre de uno de nuestros colaboradores de $8^{\circ}$ año. Su hijo no es hablante y sólo posee algunas competencias receptivas como la mayoría de sus compañeros, cuyos padres no hablan chedungun. Ella nos señaló que, si bien es cierto el chedungun es muy importante para ellos, es gracias al castellano que los niños pueden tener otras opciones para salir de la comunidad y de la pobreza.

15 En este mismo sentido, Fishman (1982) sostiene que uno de los esfuerzos más esenciales en la recuperación ha de ser la transmisión familiar de la lengua, sin lo cual todo lo demás, incluida la enseñanza formal o la presencia de la lengua en los medios de comunicación, deja de tener sentido.

${ }^{16}$ Según nos informaron las directoras de los establecimientos, el PEIB en la escuela de Ranquilhue está funcionando desde el año 2004 y en Primer Agua desde el año 2003 a la fecha. En ambos establecimientos, la enseñanza de la lengua y la cultura se ha impartido en todos los niveles, de $1^{\circ}$ a $8^{\circ}$ básico, de manera general, con muy pocas horas de clases a la semana y a cargo, principalmente, del educador tradicional. Sin embargo, el MINEDUC implementó, a partir del año 2010, la enseñanza de la lengua indígena a través de la creación del subsector de lengua indígena que se inició en los primeros niveles. En esta nueva etapa se promueve el desarrollo del bilingüismo aditivo, es decir, un enfoque de enseñanza de segunda lengua que tiene como aspiración desarrollar en los alumnos competencias lingüísticas y comunicativas en ambos idiomas (www.mineduc.cl).
} 
en mapudungun que presentan estos estudiantes, lo que es consistente con los abundantes procesos de transferencia y pérdida fonológica que se han constatado en sus sistemas lingüísticos (Henríquez, 2013).

Para finalizar el análisis de esta dimensión, presentamos algunas declaraciones de los educadores tradicionales sobre el tema en cuestión, información que viene a complementar los datos proporcionados por los niños.

\begin{tabular}{|l|l|}
\hline Declaración Asesor cultural o Educador tradicional & Localidad \\
\hline $\begin{array}{l}\text { "Hay colonos [no pewenches] aquí y hablan su chedungun, pero } \\
\text { correctamente". }\end{array}$ & Butalelbun \\
\hline $\begin{array}{l}\text { "Yo, sólo hago reforzamiento a los niños porque ellos ya hablan su } \\
\text { lengua". }\end{array}$ & Butalelbun \\
\hline $\begin{array}{l}\text { "Hay como tres o cuatro papás [de niños de } 7^{\circ} \text { y } 8^{\circ} \text { ] que no hablan. } \\
\text { Pero como le digo, los jóvenes de } 30 \text { años para abajo ya no lo ha- } \\
\text { blan". }\end{array}$ & Cauñicu \\
\hline $\begin{array}{l}\text { "Aquí, hay papás que saben y la mamá no sabe, pero uno de los dos } \\
\text { sabe, pero predomina siempre el castellano y entonces se acostumbra } \\
\text { así una familia. No tienen interés, porque si hubiera interés harían } \\
\text { algo para rescatar la lengua". }\end{array}$ & Cauñicu \\
\hline $\begin{array}{l}\text { "Muchas veces llegaban los apoderados reclamando y decían yo quie- } \\
\text { ro que mi hijo aprenda el puro castellano no el chedungun, porque el } \\
\text { chedungun lo sabemos perfectamente, pero generalmente eso no era } \\
\text { tan asi". }\end{array}$ & Cauñicu \\
\hline $\begin{array}{l}\text { "Bueno lo que ahora ya saben un poco más [los estudiantes] es el } \\
\text { saludo, ellos ya me saludan, me responden el saludo, ya en eso están } \\
\text { más o menos avanzados". }\end{array}$ & Primer Agua \\
\hline $\begin{array}{l}\text { "Los papás no hablan casi nada. Sólo algunos abuelos o abuelitas } \\
\text { [hablan chedungun]. La mayoría de los papás de estos niños no sa- } \\
\text { ben hablar chedungun". }\end{array}$ & Primer Agua \\
\hline $\begin{array}{l}\text { "[...] los niños ya no la hablan [chedungun] y no tienen interés [en } \\
\text { aprender la lengua], y también lo que más interés hay [es] en el idio- } \\
\text { ma castellano, porque en ese lado está el trabajo, siempre van a ir por } \\
\text { ese lado [castellano]". }\end{array}$ & Primer Agua \\
\hline $\begin{array}{l}\text { "Los niños no hablan [chedungun] porque ahora lo que se les estáá } \\
\text { enseñando en las escuelas solamente eso es lo que saben". }\end{array}$ & Ranquilhue \\
\hline "No, [no puedo hablar con los jóvenes] no me entenderían [...]". & Ranquilhue \\
\hline $\begin{array}{l}\text { "Ahora hay menos hablantes que antes. Ha habido una disminución } \\
\text { por temas que se mezclan, la religión, ya sea evangélica o católica y } \\
\text { está [...] la vergüenza de hablar la lengua mapuche.. }\end{array}$ & Ranquilhue \\
\hline
\end{tabular}


Las declaraciones de los educadores nos confirman lo anteriormente señalado. La comunidad de Butalelbun es la que muestra un mayor grado de retención del vernáculo, porque su enseñanza es generalizada en todas las familias de los niños. Así, cuando éstos ingresan a la escuela ya son hablantes muy competentes en su lengua, de ahí que el rol del educador tradicional se limite sólo a "reforzar" la lengua. Este proceso de transmisión ocurre, incluso, en las familias de matrimonios mixtos, lo que contraviene lo señalado en la literatura sociolingüística, donde se sostiene que, en estos casos, la lengua de mayor prestigio suele tener más posibilidades de sobrevivir como lengua familiar y, por lo tanto, como primera lengua de los hijos (Appel y Muysken, 1996). Sin embargo, esto no ocurre en Butalelbun, ya que los hijos de matrimonios mixtos o interétnicos entre un pewenche y un colono ("wingka") tienen como lengua principal el mapudungun. Esta es una evidencia más de la vitalidad lingüística que caracteriza a esta comunidad.

En Cauñicu, en cambio, no sucede lo mismo en este tipo de situaciones, porque predomina el castellano por sobre la lengua étnica. En efecto, como señala el educador tradicional de la zona, en aquellas familias donde sólo uno de los progenitores pewenches es hablante de mapudungun, la lengua oficial prevalece como lengua familiar, desplazando al idioma mapuche.

El patrón de retención y transmisión que se observa en Butalelbun no se replica del mismo modo en Cauñicu. En esta última comunidad existen familias que han interrumpido la transmisión, y en ellas el chedungun ha dejado de ser la lengua del hogar por excelencia. Estos datos nos permiten reafirmar lo que señalábamos anteriormente: la existencia de un proceso de desplazamiento en marcha en favor de la lengua oficial.

El relativo aislamiento geográfico de esta localidad cordillerana no parece suficiente para el resguardo de la lengua y la presión social y económica llevada a cabo principalmente a través del sistema educativo y de los medios de comunicación está dejando su huella en el comportamiento sociolingüístico de los pewenches. Esta situación de presión y competencia desigual entre las lenguas en esta comunidad es lo que se podría denominar un conflicto lingüistico.

En Tirúa, las declaraciones de los educadores confirman el escenario desfavorable para la lengua que nos habían adelantado los escolares. En ambas localidades el mayor grado de retención de la lengua está entre los adultos mayores y ancianos, mientras que entre los jóvenes se observa un uso muy precario, el que se torna casi inexistente entre los niños. Según los educadores, no habría niños hablantes de mapudungun en estas dos escuelas. La transmisión de la lengua a las nuevas generaciones se ha interrumpido. Los padres ya no están cumpliendo con este rol, pese a que existen hablantes entre ellos. De este modo, en la interacción familiar la lengua oficial parece ser el medio exclusivo de comunicación cotidiana y la enseñanza del chedungun ha pasado a manos de la escuela; es por ello que los educadores tradicionales nos indican que las escasas competencias en mapudun- 
gun que poseen los escolares son las que han sido transmitidas en esta institución. Esta interrupción altera la continuidad de la lengua, porque ya no estaría siendo adquirida de manera "natural" en el seno familiar, indicador importante de desplazamiento lingüístico (Fasold, 1996; Appel y Muysken, 1996; Siguán, 2001; Blas Arroyo, 2008).

\section{REFLEXIONES FINALES}

En ambas comunidades de Alto Bío-Bío se observa que un gran número de mapuches pewenches aún conserva su lengua, aunque se debe señalar que en Butalelbun el grado de mantenimiento es mucho mayor que en Cauñicu. Esto porque en Butalelbun ha habido una transmisión ininterrumpida del vernáculo y el nivel de conservación de esta lengua es todavía elevado, incluso entre las generaciones más jóvenes. En esta comunidad hemos observado lo que algunos denominan "bilingüismo saludable" (Crystal, 2001); es decir, la coexistencia de ambas lenguas sin aparente confrontación o competencia entre ellas y esto pareciera posible porque desempeñan funciones diferentes al interior de la comunidad. La lengua indígena predomina de manera casi exclusiva en todos los contextos familiares e íntimos, se transmite intergeneracionalmente en el hogar y prácticamente no hay individuos adultos que no la tengan como primera lengua, salvo los colonos, que son escasos.

No ocurre lo mismo en Cauñicu, donde se aprecia un ambiente familiar y escolar menos favorable al chedungun, que día tras día cede espacios comunicativos en favor de la lengua oficial. Al interior de algunas familias se ha iniciado un proceso de interrupción de su enseñanza, lo que ha provocado un cambio en el patrón tradicional de transmisión y la merma de los niveles de competencia de los escolares. En este sector, son principalmente los adultos los hablantes más competentes. Pese a ello esta lengua aún es utilizada como vehículo principal de comunicación en varias familias del sector.

Creemos que el aislamiento geográfico y social que anteriormente caracterizaba a las comunidades del Valle del Queuco en Alto Bío-Bío y que contribuía al mantenimiento de la lengua indígena, se reduce cada vez más. Esto se observa especialmente en Cauñicu, donde el contacto con la población castellanohablante de las ciudades es cada día más expedito e intenso. Butalelbun, en cambio, al ser la comunidad más alejada y aislada del valle, aún mantiene cierto distanciamiento de los centros urbanos altamente poblados como Santa Bárbara, Los Ángeles, etc., hecho que podría influir en la explicación de una situación sociolingüística más favorable al chedungun.

Se sabe que el mantenimiento de las lenguas minoritarias, incluso de aquellas con fuerte peso demográfico, pasa con frecuencia por el mantenimiento de la marginalidad de los hablantes y de los territorios indígenas (Appel y Muysken, 1996: 
57). Sin embargo, de acuerdo con lo observado durante nuestro trabajo de campo, creemos que la vitalidad de la lengua en Butalelbun va más allá del factor geográfico, pues también estaría relacionada con la existencia de un fuerte sentimiento de identidad étnica, de lealtad lingüística y de resistencia que caracteriza a la mayoría de las familias del sector. Sin embargo, se precisa seguir indagando sobre el particular en estas y otras comunidades del Alto Bío-Bío para ampliar y profundizar la discusión sobre los procesos de mantenimiento y sustitución lingüística y sus factores explicativos.

En Tirúa, la situación sociolingüística observada muestra que el contacto temprano e intenso entre las dos sociedades y sus lenguas ha dejado huellas profundas en los procesos de mantenimiento y elección lingüística. El proceso de desplazamiento lingüístico del mapudungun que se observa en ambas localidades costeras se hace evidente en el quiebre del traspaso intergeneracional entre padres e hijos, en la disminución del número de hablantes jóvenes y en la pérdida de competencia lingüístico-comunicativa de este grupo etario. Esta situación es bastante homogénea en ambas localidades.

Muchas de las familias de Primer Agua y Ranquilhue transmiten a sus hijos sólo la lengua oficial, mientras que la enseñanza del mapudungun estaría, principalmente, en manos de la escuela. Destacamos, eso sí, el rol que algunos abuelos desempeñan en la transmisión de la lengua en sus familias, actuando como pilares y como modelos lingüísticos a imitar. Sin embargo, es fundamental para la supervivencia y revitalización de la lengua en estas localidades que el conjunto de la comunidad se involucre en este proceso activamente y que cada uno de ellos desarrolle "un sentido de la responsabilidad de la transmisión" (Crystal, 2001: 135). La escuela, los profesores y los educadores tradicionales pueden ser un gran aporte o núcleo de desarrollo para la revitalización, pero probablemente no sean suficientes. Como señalan algunos especialistas, poco puede hacer la escuela si los padres no incentivan el aprendizaje y el uso de la lengua indígena en sus hogares y si, además, manifiestan actitudes negativas hacia ella (Fishman, 1982). Recordemos que el hogar sigue siendo el dominio de uso más relevante para que se concrete la transmisión intergeneracional, factor clave en la pervivencia de la lengua.

En definitiva, en este sector hemos observado que el mapudungun ha ido reduciendo drásticamente su campo de acción y se encuentra en la actualidad al alcance, principalmente, de los ancianos, quienes lo usan en ceremonias religiosas ancestrales como el ngillatun u otros eventos públicos y formales de la comunidad (reuniones, encuentros, etc.). El uso de la lengua ha quedado relegado a los niveles más formales, como la expresión religiosa, ritual, etc.

Quisiéramos señalar que estamos conscientes de las circunstancias sociales e históricas que moldean la lengua, pues ésta no sólo es un sistema de estructuras sino una construcción social. De ahí se desprende que cada caso de contacto es único y que tiene sus propias especificidades, por lo que resulta complejo com- 
parar comunidades de habla con trayectorias históricas y sociales tan disímiles como lo son Alto Bío-Bío y Tirúa. En este sentido, creemos más pertinente, especialmente si estamos en contextos de retracción lingüística, focalizar el análisis en comunidades y familias específicas de un mismo sector y aportar con más y nuevos antecedentes a la configuración de un panorama sociolingüístico general de la comunidad.

Por último, y en concordancia con lo anterior, creemos que es importante que el contacto mapudungun-castellano se aborde desde una óptica diversa y multidisciplinaria. En efecto, una explicación más acabada de los resultados del contacto requiere un marco interdisciplinar en el que deben considerarse no sólo los factores de orden lingüístico o estructural, sino también otros de carácter sociológico, histórico y cultural que definen o caracterizan a cada comunidad. Esto es recomendable porque en este tipo de situaciones se presentan procesos sociolingüísticos, así como variaciones y cambios lingüísticos sumamente complejos, los cuales son producto de la convergencia de una multiplicidad de factores.

\section{REFERENCIAS}

Appel, René y Muysken, Pieter. (1996). Bilingüismo y contacto de lenguas. Barcelona: Ariel.

Aracil, Lluis. (1965). Conflit linguistique et normalisations linguistique dans l'Europe nouvelle. Perpiñan: IRSCE.

Blas Arroyo, José Luis. (2008). Sociolingüistica del español. Desarrollos y perspectivas en el estudio de la lengua española en contexto social. Madrid: Ediciones Cátedra.

Crystal, David. (2001): La muerte de las lenguas. Cambridge: Cambridge University Press.

Dorian, Nancy. (1977). The problem of the semi-speaker in language death. International Journal of the Sociology of Language, 12, 23-32.

Durán, T., Catriquir, D. y Hernández, A. (2007). Revitalización del mapunzungun. Una visión crítica desde la educación intercultural, la sociolingüística y la antropología. En Patrimonio cultural mapunche. Derechos lingüisticos y patrimonio cultural mapunche, volumen I (pp. 107-125). Temuco: Universidad Católica de Temuco.

Fasold, Ralph. (1996). La Sociolingüistica de la sociedad. Introducción a la sociolingüistica. Madrid: Visor Libros.

Fishman, Joshua (1982). Sociología del lenguaje. Madrid: Ediciones Cátedra.

Gundermann, H.; Canihuan, J.; Clavería, A. y Faúndez, C. (2008). Perfil sociolingüistico de comunidades mapuches de la Región del Biobio, Araucanía, los Ríos y los Lagos. Informe de Investigación. Santiago: CONADI - UTEM. 
Gundermann, H.; Canihuan, J.; Clavería, A. y Faúndez, C. (2009). Permanencia y desplazamiento, hipótesis acerca de la vitalidad del mapuzugun. $R L A, 47(1)$, 37-60.

Hagège, Claude. (2002). No a la muerte de las lenguas. Barcelona: Editorial Paidós. Henríquez, Marisol. (2013). Vitalidad fonológica del mapudungun en escolares mapuches pewenches y lafkenches de la VIII Región del Bío-Bío. Tesis de Doctorado en Lingüística. Concepción, Chile: Universidad de Concepción.

Henríquez, M. y Salamanca, G. (2012). Rasgos prominentes de la fonología segmental del chedungun hablado por escolares pewenches del Alto Bío-Bío. Revista Alpha, 34, 152-172.

Hernández, Juan y Almeida, Manuel. (2005). Metodología de la investigación sociolingüistica. Málaga: Comares.

Hernández, R., Fernández, C. y Baptista, P. (2003). Metodología de la investigación. México: McGraw-Hill.

Klee, Carol y Lynch, Andrew. (2009). El español en contacto con otras lenguas. Washington, D.C.: Georgetown University Press.

Lagos, Cristián. (2012). El mapudungun en Santiago de Chile: vitalidad y representaciones sociales en los mapuches urbanos. RLA, 50 (1), 161-184.

Moreno Fernández, Francisco. (2005). Principios de sociolingüistica y sociología del lenguaje, $2^{\circ}$ edición actualizada. Barcelona: Ediciones Ariel.

Municipalidad de Alto Bío-Bío. (2006). Plan de Desarrollo Comunal de Alto BíoBío. Disponible en www.munialtobiobio.cl.

Municipalidad de Tirúa. (2009). Plan de Desarrollo Comunal de Tirúa. Disponible en www.munitirua.cl.

Nercesian, Verónica. (2007). Retracción y recuperación lingüística: El caso de un migrante wichí. Signođ Seña, 17, 163-191.

Salas, Adalberto. (1984). Textos orales en mapuche o araucano del centro-sur de Chile. Colección "Lenguas vernáculas de Chile" $N^{\circ} 1$. Concepción: Universidad de Concepción.

. (1992). El mapuche o araucano de Chile. Fonología, gramática y antología de cuentos. Madrid: Fundación MAPFRE América.

Serrano, María José. (2011). Sociolingüistica. Barcelona: Ediciones del Serbal.

Siguán, Miquel. (2001). Bilingüismo y lenguas en contacto. Madrid: Alianza Ensayo.

Silva-Corvalán, Carmen. (2001). Sociolingüística y pragmática del español. Georgetown: University Press.

Thomason, Sarah y Kaufman, Terrence. (1988). Language contact, creolization, and genetic linguistics. Berkeley/Los Angeles: University of California Press.

Vergara, Jorge Ivan y Gundermann, Hans. (2005). Descripción del contexto sociolingüistico en comunidades indígenas de Chile. Santiago: Programa EIB MINEDUC - Programa Orígenes. 
RLA. Revista de Lingüística Teórica y Aplicada, 52 (2), II Sem. 2014

Weinreich, Uriel. (1974). Lenguas en Contacto. Caracas: Universidad Central de Venezuela.

Wittig, Fernando. (2009). Desplazamiento y vigencia del mapudungún en Chile: un análisis desde el discurso reflexivo de los hablantes urbanos. RLA, 47, 135155.

Zimmermann, Klaus (1999). Política del lenguaje y planificación para los pueblos amerindios: Ensayos de ecología lingüistica. Madrid: Iberoamericana.

Zúñiga, Fernando (2007). Maudunguwelaymi am? ¿Acaso ya no hablas mapudungun? Acerca del estado actual de la lengua mapuche. Centro de Estudios Públicos, 105, 9-24. 